\title{
Ovarian torsion in a 20-year-old patient
}

\author{
Chris Martin, MD; ${ }^{*}$ Kirk Magee, $\mathrm{MD}^{\dagger}$
}

\begin{abstract}
Ovarian torsion is an uncommon gynecological emergency that requires prompt recognition and treatment. It may present with nonspecific signs and symptoms, and should be considered in any female with acute abdominal pain. The diagnosis is based on an awareness of the relevant risk factors, the clinical presentation, and a high index of suspicion. Timely investigation and management can make the difference between ovarian loss and salvage - an outcome of great importance in the population of reproductive age females.
\end{abstract}

Key words: ovarian torsion; adnexal torsion; gynecologic emergency

RÉSUMÉ

La torsion de l'ovaire est une urgence gynécologique rare qui nécessite une identification et un traitement immédiats. Elle peut être accompagnée de signes et symptômes non spécifiques et doit être évoquée chez toute patiente qui accuse une douleur abdominale. Le diagnostic est fondé sur une reconnaissance des facteurs de risque pertinents, la présentation clinique et un indice de suspicion élevé. Une investigation et une prise en charge en temps opportun peuvent permettre de sauver l'ovaire, un résultat d'une importance vitale pour les femmes en âge de procréer.

\section{Introduction}

Torsion of the uterine adnexa is a gynecological emergency that requires prompt diagnosis and emergency surgical treatment. It can involve the fallopian tube, the ovary, and other adnexal structures. ${ }^{1,2}$ Although this condition is generally viewed as uncommon, studies suggest that adnexal torsion is the 5th most common gynecological emergency, representing $2 \%-3 \%$ of acute surgical emergencies. ${ }^{3}$ Adnexal torsion can be a diagnostic challenge in the emergency department (ED), as most women present with non-specific symptoms. New advances in conservative surgical management have made early recognition critical for ovarian salvage, especially in the reproductive population.

\section{Case report}

A 20-year-old woman presented to the ED 3 hours after the abrupt onset of right lower quadrant abdominal pain radiating to her back. She described the pain as a constant severe ache that was intermittently sharp and stabbing, associated with nausea, vomiting and anorexia. Acetaminophen provided no relief, but curling into a fetal position eased some of her discomfort. She denied any other gastrointestinal or genitourinary symptoms. Her last normal menstrual period had ended 2 weeks before. She had not been sexually active within a year, was not using birth control and denied any history of sexually transmitted disease. She reported a similar episode one year earlier, which resolved spontaneously and was diagnosed as musculoskeletal pain.

*Faculty of Medicine, University of Western Ontario, London, Ont.

tDepartment of Emergency Medicine, Dalhousie University, Halifax, NS

Received: Apr. 8, 2005; revisions submitted: Jan. 11, 2006; accepted: Jan. 21, 2006

This article has been peer reviewed.

Can J Emerg Med 2006;8(2):126-9 
On arrival to the ED, she was alert, oriented and in mild discomfort. Oral temperature was $36.8^{\circ} \mathrm{C}$, respiratory rate was 16 breaths/min, heart rate was 84 beats/min, and blood pressure was 106/60 mm Hg. Her cardiovascular and respiratory examinations were unremarkable. Her abdomen was soft, with tenderness in the right lower quadrant. She had neither costovertebral angle tenderness nor hepatosplenomegaly. Rovsing's, psoas, and obturator signs were negative, and bowel sounds were normal. The pelvic exam revealed cervical motion tenderness as well as right adnexal fullness and tenderness, with no vaginal discharge. The patient's $\beta$-HCG was negative. A pelvic ultrasound was performed (Fig. 1), showing a 10-cm complex solid/ cystic mass lying superior to the bladder. The uterus and left ovary were normal, but the right ovary was not identified. Images were interpreted by the radiologist to represent a right ovarian mass torsion.

Emergent laparoscopy confirmed a right ovarian torsion secondary to a $10-\mathrm{cm}$ dermoid cyst.

\section{Discussion}

Ovarian torsion, first described by Kuestner in 1891, results from partial or complete rotation of the ovarian pedicle on its long axis, potentially compromising venous and lymphatic drainage. ${ }^{4}$ If the rotation is partial or intermittent, the venous and lymphatic congestion may subside quickly, along with symptoms. If rotation is complete and prolonged, venous and arterial thrombosis occur, ultimately causing adnexal infarction. ${ }^{4,5}$ Adnexal torsion is rarely bilateral and is more common on the right side, ${ }^{3,6}$ perhaps because the sigmoid colon leaves limited space for

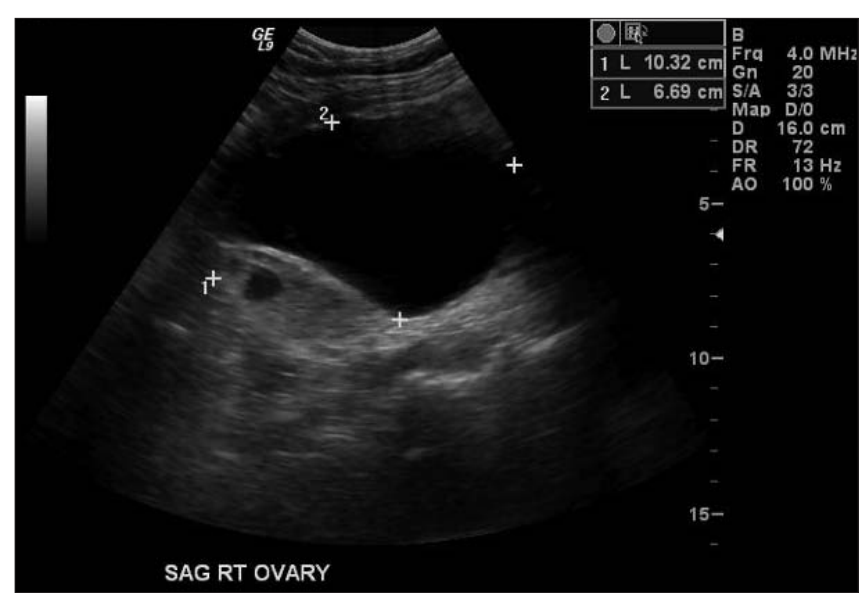

Fig. 1. $10 \mathrm{~cm}$-complex mixed solid/cystic mass situated posterior and superior to the bladder with no flow on Doppler identified within the mass. With no normal right ovary identified, it should be regarded as an ovarian mass torsion until proven otherwise. left adnexal mobility. ${ }^{7}$ Torsion occurs more commonly in young women, with the greatest incidence in the 20- to 30year age group. ${ }^{8}$

Ovarian enlargement, adnexal masses, pregnancy, ovulation induction and previous pelvic surgery are the most common predisposing factors for ovarian torsion, and the exact mechanism of torsion varies according to its cause. Ovarian enlargement of any etiology predisposes the adnexa to torsion; however, normal ovaries may undergo torsion, especially in prepubescent females. ${ }^{4}$ Ovarian tumours or adnexal masses can act as fulcrums, resulting in torsion. Benign ovarian neoplasms carry an $11 \%$ risk, and dermoid tumours (a.k.a. benign cystic teratomas), the most common ovarian neoplasms in young females, are a relatively common antecedent of adnexal torsion..$^{3,9}$ Malignant ovarian tumours are more likely to adhere to or invade other pelvic structures, hence carry a lower risk of torsion - only $2 \%{ }^{3,10}$ Because of the anatomy of the broad ligament, both the ovary (or adnexal mass) and the fallopian tube are usually involved in the torsion; it is uncommon for these structures to be involved in isolation. ${ }^{6}$

During pregnancy, the growing uterus displaces the adnexa in the face of increasingly lax supporting tissues, increasing the likelihood of adnexal torsion. This is most common between 6 and 14 weeks' gestation, and in the immediate peurperium. ${ }^{11}$ Patients undergoing ovulation induction are also at higher risk of adnexal torsion - theoretically because of ovarian enlargement from multiple maturing follicles and theca lutein cysts. ${ }^{12}$ Another predisposing factor for torsion is a hypermobile adnexa due to hydrosalpinx or an elongated mesosalpinx. Finally, previous gynecological surgery (including tubal ligation) is a risk factor for torsion because adhesions may act as pivot points upon which the adnexa can rotate. ${ }^{8}$

The diagnosis of ovarian torsion can be difficult because the presenting signs and symptoms, abdominal pain, nausea and vomiting, are common to many causes of acute abdomen, including appendicitis, bowel obstruction, gastrointestinal infection, ruptured ovarian cyst, ectopic pregnancy, pelvic inflammatory disease, cystitis and renal colic. Acute appendicitis is the most common incorrect diagnosis but, fortunately, this diagnosis does not delay surgical intervention. Non-surgical misdiagnoses such as gastrointestinal infection or pelvic inflammatory disease delay surgical intervention and may lead to adverse consequences. ${ }^{1}$ Therefore, the diagnosis of adnexal torsion must be considered in any female patient presenting with lower abdominal pain.

Classically, patients with ovarian torsion will present with acute onset of severe, progressive unilateral abdomi- 
nal or pelvic pain that is crampy or colicky in nature. ${ }^{13}$ The pain may radiate into the thigh or lower back on the affected side. ${ }^{7}$ Incomplete or intermittent torsion may be characterized by bouts of severe pain separated by asymptomatic periods as the ovary twists and untwists. ${ }^{6}$ Nausea and vomiting is common, ${ }^{3,14}$ and low grade fever $\left(<38.0^{\circ} \mathrm{C}\right)$ may occur. ${ }^{8}$ The physical exam may reveal a soft abdomen with lower quadrant tenderness; however, if the torsion is longstanding, the abdomen may be diffusely tender with peritonitis and rigidity, making localization difficult. ${ }^{7} \mathrm{Bi}-$ manual pelvic exam may demonstrate uterine shift toward the affected side. Adnexal tenderness is typical and up to $50 \%$ of women have a palpable adnexal mass. ${ }^{8}$

Few investigations are sensitive or specific for adnexal torsion, and commonly used tests are most useful to rule out other causes of lower abdominal pain. A negative $\beta$-HCG can rule out causes such as ectopic pregnancy, and a urine dipstick and microscopy should be performed to assess the possibility of urinary tract infection or stone. Studies have demonstrated elevated white blood cell counts in $16 \%$ to $38 \%$ of cases ${ }^{1,8}$ but this result is of little value in differentiating ovarian torsion from other causes of abdominal pain.

In cases of suspected torsion, immediate ultrasound is the investigation of choice, and $>93 \%$ of patients with ovarian torsion will have abnormal ultrasound findings. ${ }^{8}$ Findings depend on the duration of torsion and the degree of ovarian ischemia, ${ }^{10}$ with the most common finding ovarian enlargement. ${ }^{6}$ In cases of incomplete ovarian torsion, ultrasonography may show massive ovarian edema due to compromise of lymphatic drainage, without ischemic necrosis. ${ }^{5}$ Free fluid is found in the cul-desac in a small number of patients from ovarian capsule transudate secondary to lymphatic and venous obstruction. ${ }^{11}$ In the early stages of ovarian torsion, the ovary is enlarged with prominent peripheral follicles. Hyperechogenic and hypoechogenic areas may be seen which correspond to hemorrhage and edema respectively. With prolonged and complete torsion, infarction may appear as cystic, clotted areas. ${ }^{2}$

Colour Doppler sonograpy (CDS) has been used increasingly in recent years to evaluate ovarian viability. Abnormal flow on CDS increases the likelihood of torsion, ${ }^{6,9}$ but torsion may occur with incomplete vascular obstruction; therefore, evidence of vascular flow does not rule out torsion with certainty. ${ }^{8}$ In one recent case series, 14 of 15 patients with ovarian torsion had abnormal CDS flow patterns, ${ }^{6}$ but in another small retrospective series of 10 surgically confirmed cases, CDS often showed normal ovarian flow, and this test was associated with significant delays to diagnosis (5.3 v. 59 hours).$^{15}$
Diagnostic laparoscopy is indicated when there is a high suspicion of ovarian torsion and the need for surgical intervention remains unclear. ${ }^{13}$ Experienced laparoscopists may be able to manage an ovarian torsion through a laparoscope, but larger adnexal structures or relative inexperience with the laparoscope will require conversion to laparotomy. In the past, oophorectomy was considered the standard of care, because of concern that untwisting of the adnexa might precipitate pulmonary embolism from a thrombosed vein. ${ }^{3}$ Several studies have shown that in the absence of a grossly necrotic ovary, untwisting of the adnexa can be performed, and the ovary salvaged, without significant risk of thromboembolism. ${ }^{16,17}$ Conversely, an obvious hemorrhagic infarction or gangrenous adnexal structure requires surgical removal without attempt to untwist.

\section{Conclusion}

Ovarian torsion is a surgical emergency that often presents a difficult diagnostic challenge. A detailed history and physical, including a pelvic exam is crucial, and ancillary tests such as $\beta$-HCG are useful to exclude other possibilities. Ultrasound with or without Doppler imaging may be helpful; however, direct laparoscopic visualization is the only way to confirm the diagnosis. New advances in conservative surgery have made rapid investigation imperative, since the ability to save a viable ovary is time dependent.

Competing interests: None declared.

\section{References}

1. Haskins T, Shull B. Adnexal torsion: a mind-twisting diagnosis. South Med J 1986;79:576-7.

2. Holschneider $\mathrm{CH}$. Surgical diseases and disorders in pregnancy. In: DeCerney A, Nathan L, editors. Current obstetrics and gynecology diagnosis and treatment. New York: McGraw-Hill; 2003. p. 459-60.

3. Hibbard LT. Adnexal torsion. Am J Obstet Gynecol 1985;152: 456-61.

4. Coleman B. Transvaginal sonography of adnexal mass. Radiol Clin North Am 1992:30:677-91.

5. Warner MA, Fleisher AC, Edell SL, et al. Uterine adnexal torsion: sonographic findings. Radiology 1985;154:773-5.

6. Albayram F, Hamper UM. Ovarian and adnexal torsion: spectrum of sonographic findings with pathology correlation. J Ultrasound Med 2001;20:1083-9.

7. Nichols DH, Julian DJ. Torsion of the adnexa. Clin Obstet Gynecol 1985;28:375-80.

8. Houry D, Abbot JT. Ovarian torsion: a fifteen year review. Ann Emerg Med 2001;38:156-9.

9. Morrison L, Spence J. Vaginal bleeding and pelvic pain in the non-pregnant patient. In: Tintinalli J, Kelen GD, Stapczynski JS, editors. Emergency medicine: a comprehensive study guide. 5th ed. New York: McGraw-Hill; 2000. p. 669-80. 
10. Webb EM, Green GE, Scoutt LM. Adnexal mass with pelvic pain. Radiol Clin North Am 2004;42:329-48.

11. Cappell MS, Friedel D. Abdominal pain during pregnancy. Gastroenterol Clin North Am 2003;32:1-58.

12. Gorkemli H. Adnexal torsion after gonadotrophin ovulation induction for IVF or ICSI and its conservative treatment. Arch Gynecol Obstet 2002;267:4-6.

13. Burnett LS. Gynecological causes of the acute abdomen. Surg Clin North Am 1988;68:385-98.

14. Morgan A. Genitourinary emergencies: adnexal mass evaluation in the emergency department. Emerg Med Clin North Am 2001;19:799-816.
15. Pena JE, Ulfberg D, Cooney N, et al. Usefulness of Doppler sopnography in the diagnosis of ovarian torsion. Fertil Steril 2000;73:1047-50.

16. Cohen SB. Laparoscopic detorsion allows sparing of the twisted ischemic adnexa. J Am Assoc Gynecol Laparosc 1999;6:139-43.

17. Zweizig S, Perron J, Grubb D, et al. Conservative management of adnexal torsion. Am J Obstet Gynecol 1993;168:1791-5.

Correspondence to: Dr. Kirk Magee, Department of Emergency Medicine, 3021 Halifax Infirmary, QE II Health Sciences Centre, 1796 Summer St., Halifax NS B3H 3A7

\title{
Calendar • Calendrier
}

\section{CAEP 2006 Roadshows}

\section{Register online for CAEP events. Additional sites may be arranged upon request. www.caep.ca}

\begin{abstract}
AIME: Airway Interventions \& Management Education
Toronto, Ont. [prior to North York EM Update] Halifax, NS [prior to ICEM 2006]

May $3 \& 4$

June $2 \& 3$
\end{abstract}

\section{EDTU - ED Targeted Ultrasound}

Antigonish, NS

Halifax, NS [prior to ICEM 2006]

Muskoka, Ont.

April 22

June $2 \& 3$

July 8 \& 9

\section{ED STAT! - ED Strategies for Teaching Any Time}

\section{Calgary, Alta.}

Thunder Bay, Ont.

Prince George, BC

San Francisco, Calif. [at SAEM]

Halifax, NS [prior to ICEM 2006]

\section{Kids CAEP-ERs: a Day in the ED}

Cambridge, Ont. [prior to Tri-City EM Conference] Summerside, PEI

Regina, Sask.

Mar. $20 \& 21$

Mar. 25

Apr. 22

May 20

June 3

Roadshows info: Janice Maclsaac, CME Coordinator; 800 463-1158 x20, fax 613 523-0190, cme-

registration@caep.ca

\section{ICEM 2006}

\section{1th International Conference on EM}

Halifax, NS

June 3-7

Contact: Compart Event Management; 902 454-4714, fax 902 454-4930, icem2006@compartevents.com; www.icem2006.com

\section{Other CME Programs}

\section{EM \& Acute Care Series}

Costa Rica

Mar. 9-13

Orlando, Fla.

Apr. 27-30

[discounted $\$ 100$, with pay't to EMA by credit card in US funds] Contact: Emergency Medical Abstracts; 800 458-4779.

Go to www.ccme.org for complete list of courses.

\section{Tri-City ER Conference}

Holiday Inn, Cambridge, Ont.

Mar. 29

Contact: Guelph General Hospital; 519 837-6440 ×2588,

kcrawford@gghorg.ca

\section{Herb Parkin Day in EM 2006}

Coquitlam, BC

Mar. 31

Contact: Medical Education Department, Royal Columbian Hospital; 604 520-4211, Barb.Geddes@fraserhealth.ca

\section{Paediatric Update 2006}

Hospital for Sick Children, Toronto, Ont. May 1-6 Contact: CME; brenda.rau@sickkids.ca, www.sickkids.ca/Health careProfessionals/default.asp

\section{North York EM Update}

Royal York Hotel, Toronto, Ont.

May 4-6

Contact: North York General Hospital Conference Services;

Mar. 28

May 10

May 26

416 635-2522, cme@nygh.on.ca, www.nygh.on.ca

\section{Society for Academic Emergency Medicine (SAEM)} Annual General Meeting

San Francisco, Calif. May 18-21

Contact: 517 485-5484, fax 517 485-0801, saem@saem.org

\section{Child Maltreatment Conference}

Hospital for Sick Children, Toronto, Ont.

June $8 \& 9$

Contact: CME; brenda.rau@sickkids.ca, www.sickkids.ca/Health careProfessionals/default.asp

\section{Congrès scientifique de MU}

Centre des congrès de Québec

Oct. 24-27

Contactez : L'Association des médecins d'urgence du Québec; 418 658-7679, amuq@amuq.gc.ca, www.amuq.gc.ca

Don't forget! CAEP 2006 is ICEM 2006. For more information visit www.caep.ca and click on ICEM2006. 